\title{
A multivariate random forest approach to the cognitive hierarchy: testing for the effects of postmodernization by simultaneously considering recreational hunting and volunteering with animals.
}

\author{
Cerri J. ${ }^{1}$, Procaccio E.L. ${ }^{1}$, Ferretti M. ${ }^{1}$, and Mori E. ${ }^{1}$ \\ ${ }^{1}$ Istituto per la Protezione e la Ricerca Ambientale (ISPRA), Via del Cedro, 57122, Livorno, Italy. email: jacopo.cerri@isprambiente.it \\ 22. Università degli Studi di Pavia, Dipartimento di Scienze della Terra e dell'Ambiente, Via Ferrata 5, Pavia, Italy \\ ${ }^{3} 3$. Regione Toscana, Corso Gramsci 110, 55110, Pistoia, Italy \\ 44. 4. Università degli Studi di Siena, Dipartimento di Scienze Fisiche, della Terra e dell'Ambiente, Via Mattioli 4, 53100, Siena, Italy
}

July 16, 2021

In postmodern societies socioeconomic changes characterizing the last decades shifted value orientations and attitudes towards wildlife, diminishing consumptive uses of wildlife, such as recreational hunting or fishing. However, no study has tested yet whether the same forces of modernization also increased nonconsumptive uses of wildlife. We adopted multivariate random forests to model the effect of urbanization, average income and higher education over the conjoint incidence of recreational hunters and people who volunteer with animals at the municipal scale, in Tuscany (Central Italy). We also used timeseries analysis to see if these effects were supported by long term trends in recreational hunting across different areas. Urbanized areas, characterized by higher proportion of residents with a higher education, are negatively associated with the incidence of recreational hunters, and positively to the incidence of people volunteering with animals. Cluster analysis identified two groups of municipalities, characterized by opposite incidences of hunters and volunteers, by a different magnitude of change in recreational hunting and by a different level of urbanization. Although hunting participation declined steadily over the last 15 years, this decline was greater at urbanized municipalities. These differences are likely to produce conflicts about wildlife management, and we believe regional agencies should adopt preemptive measures to mitigate them, such as improved data sharing and staff training about human dimensions of wildlife. Our findings indicate that the cognitive hierarchy can be a valuable theoretical frame to link socioeconomic dynamics to changes in human-wildlife relationships, even for non-consumptive wildlife uses.

cognitive hierarchy | wildlife value orientations | postmodernization | hunting | volunteering

Correspondence: jacopo.cerri@isprambiente.it

\section{CAUTION}

The following manuscript is a preprint: it has not been peer-reviewed yet. We shared it to maximize its accessibility, to increase the transparency of the review process and suggestions will be appreciated. But this is not a peer-reviewed study. If you do not know what a preprint is, we encourage you to read this page: https://help.osf.io/hc/en-us/articles/ 360019930493-Preprint-FAQs\#what_is_a_preprint This study was published on Human Dimensions of Wildlife, the $18^{\text {th }}$ of October 202. Please cite it as: "Cerri, J., Procaccio, E. L., Ferretti, M., Mori, E. (2020). Modernizationinduced socio-economic changes and their effect over the spatial distribution of recreational hunting and volunteering with animals. Human Dimensions of Wildlife, 1-10. https://doi.org/10.1080/10871209.2020.1825878" .

\section{Introduction}

Over the last few decades, Western countries faced a largescale shift in basic human values, which changed from materialist to post-materialist ones, due to increased income, higher levels of education and urbanization (Inglehart, 1997).

This shift had major social and political implications, as it affected many different phenomena, like politics, selfexpression, environmentalism, economic growth, leisure, affective relationships, marriages, divorces and gender roles (Granato et al., 1996; Inglehart, 1997, 2000, 2008; Inglehart and Welzel, 2010; Van de Kaa, 2001). This shift also changed human-wildlife relationships. Notably, modernization was found to affect wildlife value orientations (WVO), belief networks providing specificity to general human values and governing their effect over attitudes and behaviour concerning wildlife. Domination WVO makes people regard wildlife as a resource, which should be mastered to maximize human well-being, even if animals suffer. On the other hand, mutualistic WVO make people consider wild animals as sentient creatures deserving full consideration and possessing rights similar to those of humans (Manfredo et al., 2003, 2009). In the United States, modernization produced a shift towards mutualistic WVO, with consequences over the public support for wildlife management initiatives, attitudes towards wildlife and trust towards governmental policies (Manfredo et al., 2009, 2016, 2017a; van Eeden et al., 2017). However, some rural areas were left behind by modernization, and are still characterized by large social groups with dominationoriented WVO, whereas others host substantial groups of either traditionalists and mutualists. This spatial heterogeneity poses new challenges to conservationists: the rural-urban divide makes it hard to develop shared and inclusive wildlife policies, while areas with segregated groups with polarized attitudes towards wildlife are prone to social conflicts over wildlife and its management (Manfredo et al., 2017b). WVO were found to predict human attitudes and behaviour towards wildlife even outside North America, e.g. in most European countries (Cerri et al., 2017; Gamborg and Jensen, 2016; Her- 
mann et al., 2013; Kaltenbron et al., 2017; Jacobs et al., 2014; Raadik and Cottrell, 2007; Sijtsma et al., 2011; Teel et al., 2010) and in some non-Western countries (Zainal Abidin and Jacobs, 2016; Zinn and Shen, 2007). The classic predictions of the cognitive hierarchy, on the effect of socio-economic changes over the observed decrease in recreational hunting, were found to be valid for Italy and Netherlands (Cerri et al., 2018; Vaske et al., 2011). Therefore, the cognitive hierarchy seems to be a valuable theoretical frame to explore how modernization can produce long-term changes in the relationship between society and wildlife, or more broadly, between society, nature and its conservation.

However, the cognitive hierarchy still has one major gap: to date, researchers focused mostly on consumptive wildlife uses only, such as recreational angling or hunting. To the best of our knowledge, no study explored how well the cognitive hierarchy can generate predictions about the effects of modernization over those behaviours which enhance the well-being of animals, like animal rights activism or animal protection. Mutualists disapprove hunting and can support petitions against it, but they should also support and get involved in those activities that maximize animal well-being. Although some of these activities are constrained by practical barriers (e.g. the existence of wildlife centres or protected areas), others are relatively unconstrained and depend mostly upon individual willpower (e.g. joining an NGO which manages a dog house). Therefore, their diffusion should be strongly affected by large-scale shifts in socioeconomic conditions and mutualism. However, no study has yet tested for this prediction, nor explored how modernization can produce spatially-explicit patterns of hunting participation and animal volunteering.

Our work aims to address this gap, by exploring the predictive power of the cognitive hierarchy for predicting the effects of socio-economic changes over recreational hunting and membership to animal protection NGOs. Notably, we will address three research questions: i) does increased income, education and urbanization lead to a diminished participation in recreational hunting?, ii) does increased income, education and urbanization lead to higher levels of volunteering with animals? iii) do these relationships reflect a value shift?

\section{Methods}

A. Study area. The study area includes the Tuscany region, in Central Italy. Tuscany includes 273 municipalities, covering a surface of $22985 \mathrm{~km}^{2}$. The region hosts the highest number of recreational hunters in Italy, who nevertheless declined by approximately $37 \%$ between 2001 and 2017 (Fig. 1). The last demographic data about hunters, collected in 2011 , showed that $52.2 \%$ of hunters at that time were more than 50 years old and $24.0 \%$ were more than 70 years old. In the study area, hunting can be practised by people holding a valid license on public land and most private properties, by paying a yearly fee. Private hunting estates exist but cover a minority of the total surface which is eligible for hunting. Game is regarded as a public good, and privates cannot ex-

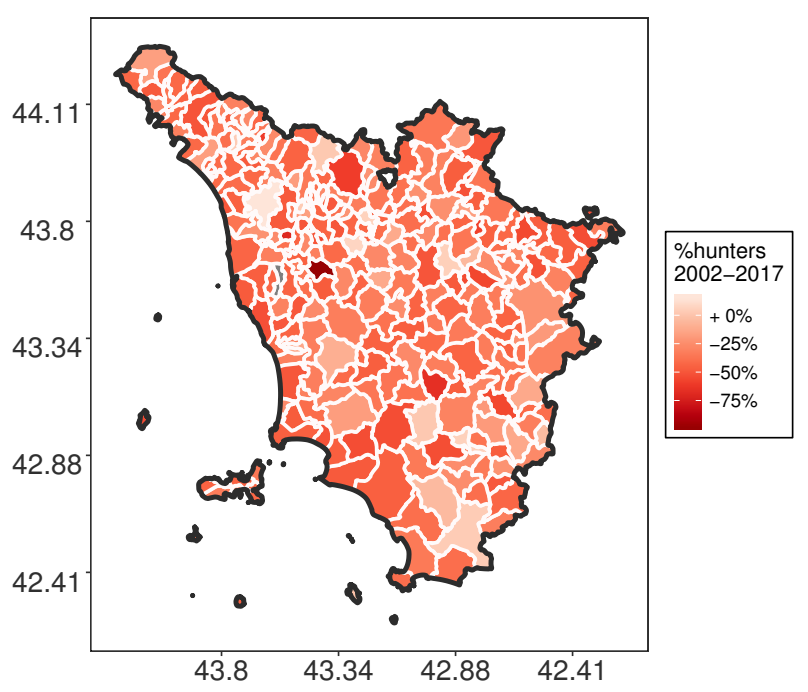

Fig. 1. Map of the study area: the decrease in recreational hunting between 2001 and 2017.

ercise property rights on wildlife. Traditional forms of hunting targeted mostly small game and migratory bird species. However, the decline in small game and the strong increase in wild ungulates, deer species and the wild boar, shifted hunting habits. Nowadays, deer stalking and boar hunting are the most important forms of hunting and recreational hunting and voluntary wildlife control coexist. As wild ungulates damage croplands (damages, approx. $1 \mathrm{mln} € /$ year in 2018), and professional hunting is illegal in Italy, hunting revenues from licenses contribute to compensate for crop -damaging and recreational hunters volunteer in control schemes, for the eradication of wild ungulates from selected areas.

On the other hand, information about NGOs for animal protection and animal right activism are scarcer. Italy surveyed non-profit organizations, such as NGOs, in 1999 and 2001, and the second national survey was carried out in 2011, with different criteria (Barbetta, Ecchia e Zamaro, 2016). Data from the 2011 census are the only available at the municipal scale and they indicate that in Tuscany 130 NGOs focused on animal protection and the defence of animal rights. Overall, these NGOs relied on 2763 volunteers. Although some animal rights activists operate outside of registered NGOs, and their number is unknown, they are likely to be a tiny minority of the total (Bertuzzi et al., 2019).

B. Data and hypotheses. To avoid hypothesizing after the results are known (HARKING, Hollenbeck and Wright, 2017), we pre-registered our research idea and protocol (Nosek et al. 2018) on the website of the Open Science Foundation. The research protocol is available at osf.io/ fj238.

Following Manfredo et al. (2009) we measured modernization by its three main components: urbanization, income and education. Urbanization was measured as the proportion of the urbanized surface of each municipality. Income was measured as the average value of the eligible income for each municipality (IRPEF, i.e. the Italian personal income tax). Ed- 
ucation was measured as the proportion of residents in each municipality who have a high school diploma or a university degree. Hunting participation was measured as the incidence of recreational hunters over the resident population, namely the number of hunters out of 1000 adult residents. The incidence of volunteers at animal protection NGOs was measured in the same way (Fig. 2). We used data from 2011, as it was the only year when information about NGOs from the national survey was available. We tested for the following hypotheses:

- $\mathrm{H}_{1}$ ) urbanization would show a strong negative relationship with the rate of recreational hunters;

- $\mathrm{H}_{2}$ ) average income would show a negative relationship with the rate of recreational hunters;

- $\mathrm{H}_{3}$ ) education would show a negative relationship with the rate of recreational hunters;

- $\mathrm{H}_{4}$ ) average income and urbanization would have an interactive effect on the rate of recreational hunters, with poorer and highly rural areas scoring the highest in terms of recreational hunters;

- $\mathrm{H}_{5}$ ) urbanization would show a strong positive relationship with the rate of people who volunteer in animal protection NGOs;

- $\mathrm{H}_{6}$ ) average income would show a positive relationship with the rate of people who volunteer in animal protection NGOs;

- $\mathrm{H}_{7}$ ) education would show a weakly positive relationship with the rate of people who volunteer in animal protection NGOs;

- $\mathrm{H}_{8}$ ) median income and urbanization would have an interactive effect on the rate of people who volunteer in animal protection NGOs, with wealthier and highly urbanized areas scoring the people who volunteer in animal protection NGOs;

- $\mathrm{H}_{9}$ ) hunters, from 2002 to 2017, experienced the highest decline in areas that in 2011 had many volunteers and few hunters;

- $\mathrm{H}_{10}$ ) hunters, from 2002 to 2017, experienced the lowest decline in areas that in 2011 had few volunteers and many hunters;

C. Statistical analysis. Before any statistical analysis, we tested for spatial correlation through Moran's I and Moran's correlograms (Plant, 2012). We found no evidence of spatial correlation. Correlation indexes, significance tests and correlograms are available in the supplementary material (S1). However, to account for large-scale spatial trends in model variables, we included latitude and longitude of municipal centroids as covariates in our model.

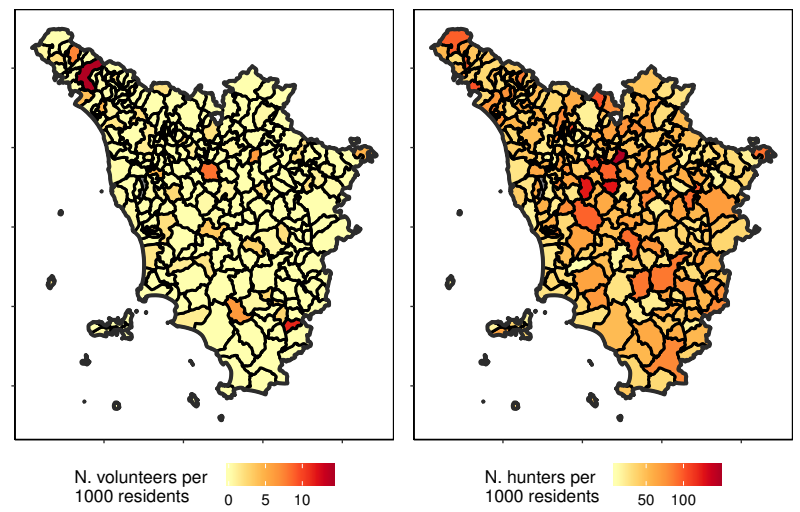

Fig. 2. Map of the study area: municipal participation rates (n.cases every 1000 residents) for recreational hunting and animal welfare volunteering. Data refers to 2011.

We modelled the effect of urbanization, income and education over the incidence of recreational hunting and volunteering in animal protection NGOs by means of multivariate random forests (Segal and Xiao, 2011). Conventional random forests, combining multiple regression trees, produce interpretable predictions by dividing data into homogeneous subgroups characterized by similar values of the response variable and the predictors, usually subgroup means for continuous variables. Multivariate random forests extend the application of random forests to more than one response variable, enabling researchers to model the effect of covariates over a subset of responses. By doing so, and not by modelling response variables separately, multivariate random forests are able to detect shared patterns of responses to covariates (Ferrier and Guisan, 2006). We calculated variable importance, as our model randomly permuted the values of predictors and evaluated the change in the Mean Squared Error (MSE, Breiman, 2001), and we used partial dependence plots to graphically represent the marginal effect of covariates over the two responses.

Then, we extracted the proximity matrix from the random forest model, which represents a measure of similarity between observations, and we performed PAM cluster analysis to identify groups of municipalities characterized by similar trends in the incidence of recreational hunters (20022017) differed between the different clusters of municipalities. We used the silhouette-width method to identify the optimal number of clusters (Kassambara, 2017)

To conclude, we tested whether temporal trends in the incidence of recreational hunters (2002-2017) differed between the different clusters of municipalities. We fitted a linear regression with a normal distribution of the error, by using a variable assigning each municipality to a specific cluster and the year as predictors. A first-order autocorrelation structure was sufficient to account for temporal autocorrelation between observations, as shown by the temporal variogram.

\section{Results}

Our random forest model supported most of the hypotheses that were advanced and it explained $62.64 \%$ of the variabil- 
ity in the two response variables. Partial dependency plots revealed that urbanization showed a marked negative, nonlinear, association with the incidence of recreational hunters. At the same time, urbanization showed a specular pattern, a positive nonlinear association with the incidence of residents who volunteered in animal protection NGOs. Another couple of opposite patterns also emerged when we considered education: the number of respondents with higher education was negatively associated with the incidence of hunters, while it was positively associated with the number of volunteers. Hypotheses $\mathrm{H}_{1}, \mathrm{H}_{3}, \mathrm{H}_{5}$ and $\mathrm{H}_{7}$ were therefore accepted. On the other hand, our hypotheses about the effect of income $\left(\mathrm{H}_{4}\right.$, $\mathrm{H}_{6}, \mathrm{H}_{8}$ ) were rejected: income showed a positive relationship with the incidence of recreational hunting, as well as a U-shaped association with the incidence of volunteers (Fig. 3 ). In terms of variable importance, the proportion of urbanized areas was the most important predictor for the incidence of recreational hunting at the municipal scale, while average income and education were the most important predictors for volunteering.

PAM cluster analysis and the silhouette method revealed the presence of two groups of municipalities (Fig. 4). The first cluster showed a higher median incidence of recreational hunters (66.97 hunters every 1000 adult residents) and a lower incidence of volunteers ( 0.24 hunters every 1000 adult residents), compared to the second cluster (hunters $=35.38$, volunteers $=0.65$ ).
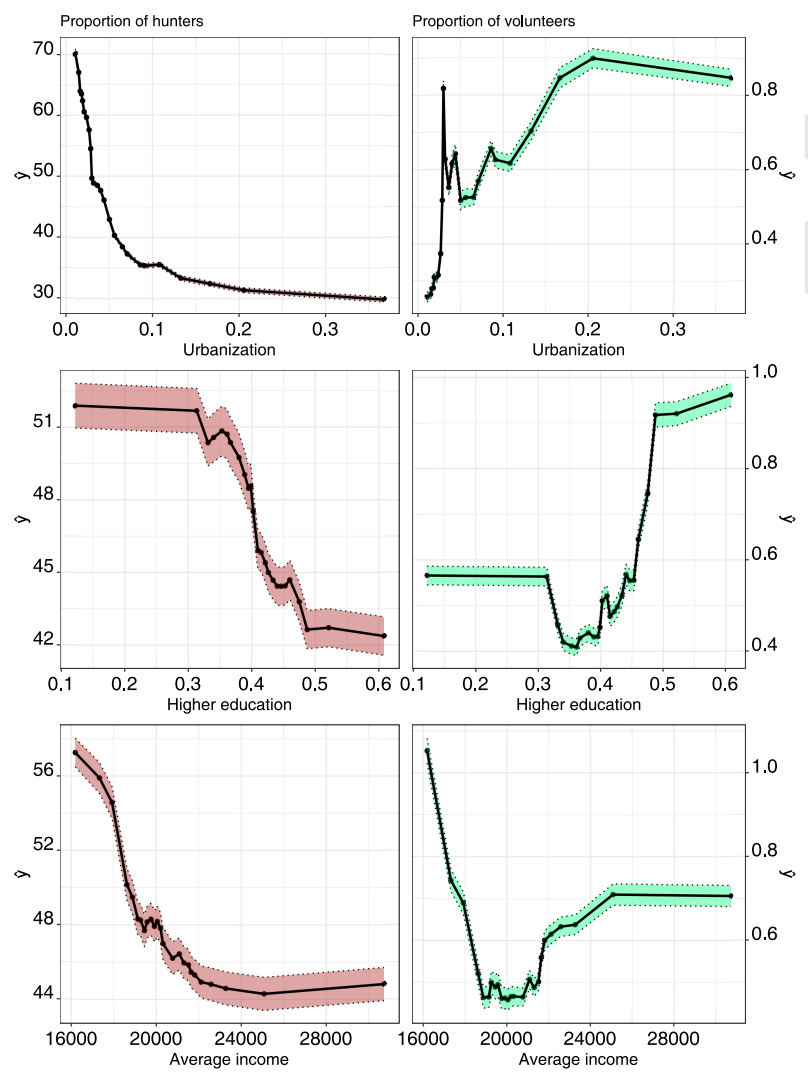

Fig. 3. Partial dependency plots from the multivariate random forest algorithm. Effect of the proportion of urbanized surface (a), the proportion of residents with a higher level of education (b) and the median income per year (c) over the incidence of recreational hunters (left panel) and animal welfare volunteering (right panel). Incidence is expressed as the number of hunters/volunteers per 1000 residents.
Time-series analysis, based on the linear regression revealed significant differences in the decline of the incidence of recreational hunters over the adult population, between 2002 and 2017. Hunters declined steadily throughout all the municipalities of the two clusters. However, the average incidence of recreational hunting was consistently lower at municipalities from the second cluster, where volunteers were more abundant in 2011. These municipalities also faced a higher overall variation in the incidence of hunters (median $\pm \mathrm{sd}=$ - $0.42 \pm 0.09$ ), compared to those who had more hunters in 2011 (median $\pm \mathrm{sd}=-0.29 \pm 0.16$; Fig. 5 ).

Municipalities from the two clusters also differed in their average proportion of urbanization, with municipalities from cluster 2 that were more urbanized (median $\pm \mathrm{sd}=0.02 \pm$ 0.00 ) than municipalities from cluster 1 (median $\pm \mathrm{sd}=0.07$ \pm 0.07 ). A complete map of the two groups of municipalities is available in Fig. 6.

\section{Discussion and conclusions}

To the best of our knowledge, this study is the first where predictions from the cognitive hierarchy about the consequences of modernization over human-wildlife relationships, were tested through a conjoint analysis of consumptive and nonconsumptive wildlife uses. We believe that this approach provides a robust evaluation of the cognitive hierarchy as a theoretical framework, as preexisting studies focused mostly the effect of value shifts over attitudes towards wildlife (Gamborg et al., 2019; Hermann et al., 2013; Jacobs et al., 2014; Sijtsma et al., 2011), or considered only consumptive wildlife uses, like recreational hunting (Cerri et al., 2017, 2018). Although attitudes are antecedents of human behaviour, over the last few years researchers emphasized the need to focus on human behaviour directly, to develop sounder theoretical frames that can better inform policymakers about the consequences of social changes and conservation policies (Nilsson et al., 2019). By considering two behaviours which lie as opposites in the spectrum of human-wildlife interactions, we believe to have provided strong evidence for the cognitive hierarchy and its predictions on the effects of modernization on human-wildlife relationships. Although we did not carry out any mediation analysis, which is challenging in non-experimental studies (Bullock and Ha, 2011), our findings perfectly align with what would be expected from a mediating effect of wildlife value orientations between value changes and attitudes/behaviour towards wildlife. When areas become more urbanized and characterized by a higher level of education, the number of people who engage in recreational hunting decreases, while we observe an increase in those who decide to engage in activities which enhance the well-being of animals, e.g volunteering for animal protection NGOs (Manfredo, 2008; Manfredo et al., 2009).

Our multivariate random forest model relied on data from only one year, but cluster analysis and time-series modelling complemented it, providing further support for its outputs: we identified two distinct groups of municipalities, that differed in their incidence of hunters and volunteers in 2011, but who also differed in hunting participation over a 15- 

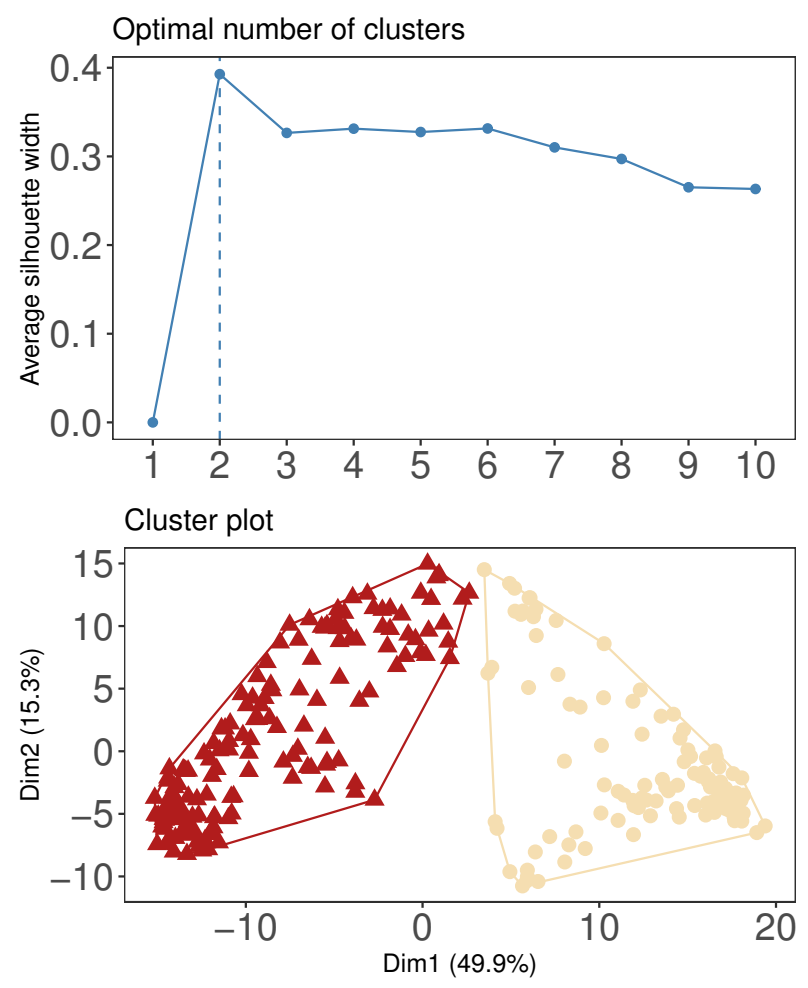

Fig. 4. PAM algorithm cluster analysis: silhouette width (top panel) and clusters of municipalities (bottom panel): Cluster 2 (red, on the left) and Cluster 1 (white, on the right)

years long timespan. Notably, rural municipalities had more hunters in 2011 and faced a smaller decline in hunting participation between 2002 and 2017. We believe that these findings could have been even more extreme, if we had data from a longer timespan. In fact, our data starts in the early 2000s, after many decades of shifting values and wildlife value orientations, when the number of recreational hunters in Italy had already halved from the 1980s (Ministero delle Politiche Agricole, Alimentari e Forestali, 2009).

However, our expectations about the association between median income and the incidence of hunters and volunteers was not supported by the data. While we expected recreational hunters to decrease with increasing incomes, the opposite was true. Moreover, we observed a complex, nonlinear association with volunteers. These findings could have depended upon the small geographical scale of some municipalities, as well as on the dynamics that occur during rural abandonment. In Tuscany, some municipalities have a few hundreds of residents only: in these conditions median income is probably prone to some bias due to extremely wealthy residents. Moreover, although many rural areas of Tuscany are being abandoned and marginalized, facing hard economic conditions (Sallusti et al., 2018), they also face the emigration of their younger residents. As young people are also those who shifted their values, it is easy to see how their emigration from poor areas might contribute to blur the effect of poverty over human-wildlife interactions. These two issues could be mitigated in cross-sectional studies, only by adopting larger geographical scales, such as provinces. At these scales, more complex metrics of economic development are

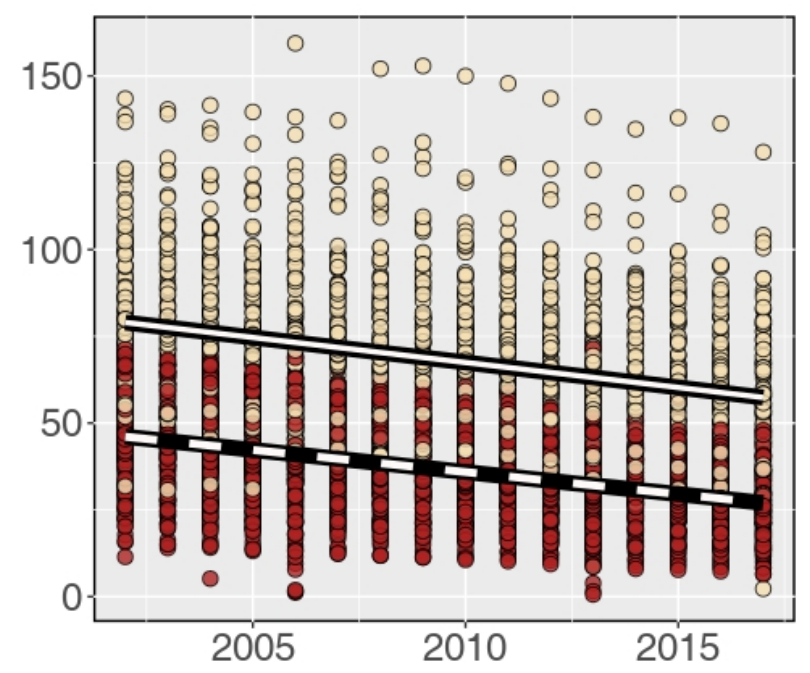

Fig. 5. Number of hunters every 1000 residents in the two clusters (cluster: 1 solid line; cluster 2:, dashed line) between 2002 and 2017.

available (Calcagnini and Perugini, 2019) and the effect of emigration and small samples is probably lower.

Our findings also raise concerns about the difficulties that will affect wildlife management in the Tuscany Region, during the next few years. Wildlife will be managed in an increasingly fragmented context, where municipalities are becoming progressively separated in their hunting participation rate and in the number of people who endorse animal rights activism and animal protection. Municipalities hosting volunteers from NGOs are more urbanized than strongholds of recreational hunting. This divide will certainly affect wildlife management, just as it was already seen in North America and other European countries: some portions of the society will conflict over intrusive forms of wildlife management such as lethal control, over the legitimacy of hunting on private properties and over the credibility of management agencies and policies (Manfredo 2008; Manfredo et al., 2009, 2016, 2017a). These tensions are likely to constrain wildlife management policies and to trigger long-term social conflicts and tensions between stakeholders and agencies.

Thus, two different preemptive measures may be adopted, in the short term, to avoid the emergence and the chronicity of these conflicts. First, agencies may improve the sharing of information about wildlife management, for example by creating websites and open-access datasets about wildlife populations and hunting statistics, as well as by promoting regular informative meetings targeting diverse social groups. This would constitute a leap forward from the current situation, where information is contained in technical reports ( $\mathrm{Re}$ gione Toscana, 2012, 2017) and where communication initiatives target mostly organizations of hunters and farmers. Second, although large-scale recruitment of personnel with dedicated competences is unfeasible in the short term, providing formal training about human dimensions to wildlife technicians, who usually have a background in the life sciences, could make them more capable to handle social conflicts about wildlife and to understand their drivers. These two actions would come at a minor cost and can have a pro- 


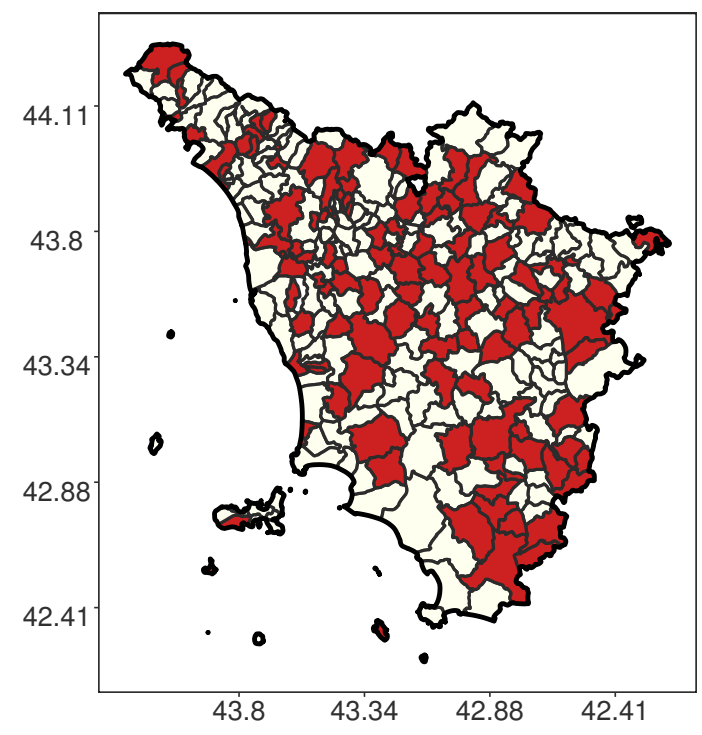

Fig. 6. Distribution of the two clusters of municipalities in the study area: cluster 1 (dark) and cluster 2 (white).

found effect over the functioning, the perceived credibility and the resilience of environmental agencies.

Our data also showed that the number of recreational hunters declined more in urbanized areas than in the countryside: this trend will probably continue in the near future, if the same socioeconomic dynamics would endure. Predicting the magnitude of this decrease will be fundamental to design effective and inclusive management policies, and to forecast the extent to which revenues from hunting licenses will decrease. However, modelling data from hunting licenses will be useless for this task (Manfredo et al., 2018) and it will be fundamental for future studies to build explicit matrix population models (Caswell, 2006) accounting for recruitment and mortality in the population of recreational hunters.

Finally, our study also emphasizes the importance of data about volunteering in animal rights and animal protection NGOs. Our data indicates that in 2011 the incidence of volunteers was relatively low at the municipal scale, much lower than that of recreational hunters. It would be interesting to see how the scenario will change in the future, whenever some data from the next national inventory of nonprofit and NGOs will be available. Recently, various authors raised concerns about the possibility of a large scale detachment from nature in Western countries, with fewer people experiencing nature and engaging in outdoor activities than in the past (Kareiva, 2008; Pergams and Zaradic, 2008; Soga et al., 2016). At a time of environmental crisis, it would be important to monitor these dynamics and to understand their determinants. Pro-environmental and animal welfare volunteering could be valuable indicators to detect them and we encourage future research exploring them and their relationships with postmodernization and value change.

In this study, we explored the conjoint response of recreational hunting and animal protection volunteering to socioeconomic changes caused by modernization in Central Italy. Our findings indicate that modernization affected both of them, producing territorial discrepancies in the incidence of

\begin{tabular}{lccr}
\hline Coef. & Values & S.E & p-value \\
\hline (Intercept) & 2963.05 & 89.44 & $* * *$ \\
Year & -1.44 & 0.04 & $* * *$ \\
Cluster (2 vs 1) & -369.15 & 116.65 & $* *$ \\
epsilon & 0.86 & 0.01 & $* * *$ \\
Year : Cluster & 0.17 & 0.06 & $* *$ \\
\hline $\mathrm{R}^{2}$ & 0.87 & & \\
Adjusted R & 0.87 & & \\
Observations (n) & 4322 & & \\
RMSE & 8.66 & & \\
\hline${ }^{* * *} p<0.001,{ }^{* *} p<0.01,{ }^{*} p<0.05$ & &
\end{tabular}

Table 1. Output of the linear regression model (with 1st order temporal autocorrelation structure)

both recreational hunters and people who volunteered for animal protection NGOs. Hunters between 2002 and 2015 decreased more at urbanized areas with highly educated residents, where animal protection volunteers were more abundant, whereas their decrease was lower in rural areas. Apart from providing a comprehensive validation of the cognitive hierarchy, as a model to understand long-term changes in human-wildlife relationships, we also believe our findings raise an alarm for wildlife managers.

In Tuscany, we are observing a rural-urban divide, which is likely to produce polarization in public attitudes towards wildlife management and social conflicts. Wildlife and environmental agencies should cope with these dynamics, anticipating their negative consequences by improving their communication policies and by providing formal training about human dimensions to wildlife technicians.

\section{ACKNOWLEDGEMENTS}

We are deeply grateful to Edoardo Bassett (University of Birmingham), who kindly revised the English language of our Manuscript.

\section{AUTHOR CONTRIBUTIONS}

Dr. Jacopo Cerri developed the research idea, supervised data structuring, carried out data analysis and contributed to writing the Ms. Mrs Eva Luna Procaccio structured the dataset, and contributed to data analysis and Ms writing. Dr. Emiliano Mori developed the research idea, supervised data structuring and analysis and took part into Ms writing and editing. Dr. Marco Ferretti contributed to the research idea, to the interpretation of results and to Ms writing.

\section{References}

Barbetta, G. P., Ecchia, G., Zamaro, N. (Eds.). (2016). Le istituzioni nonprofit in Italia: dieci anni dopo. Il mulino.

Bertuzzi, N. (2019). Contemporary animal advocacy in Italy. Modern Italy, 24(1), 1-20.

Bullock, J. G., Ha, S. E. (2011). 35. Mediation Analysis Is Harder than It Looks. Cambridge handbook of experimental political science, 959.

Breiman, L. (2001). Random forests. Machine learning, 45(1), 5-32.

Calcagnini, G., Perugini, F. (2019). A well-being indicator for the Italian provinces. Social Indicators Research, 142(1), 149-177.

Caswell, H. (2006). Matrix population models. Encyclopedia of Environmetrics, 3 .

Cerri, J., Ferretti, M., Coli, L. (2018). Where the wild things are: urbanization and income affect hunting participation in Tuscany, at the landscape scale. European journal of wildlife research, 64(3), 23.

Cerri, J., Mori, E., Vivarelli, M., Zaccaroni, M. (2017). Are wildlife value orientations useful tools to explain tolerance and illegal killing of wildlife by farmers in response to crop damage?. European journal of wildlife research, 63(4), 70.

Decker, D. J., Riley, S. J., Siemer, W. F. (Eds.). (2012). Human dimensions of wildlife management. JHU Press. 
Gamborg, C., Jensen, F. S. (2016). Wildlife value orientations: a quantitative study of the general public in Denmark. Human Dimensions of Wildlife, 21(1), 34-46.

Gamborg, C., Lund, J. F., Jensen, F. S. (2019). Landowners' wildlife value orientations, attitudes and behaviour in relation to game management practices. European journal of wildlife research, 65(1), 9.

Granato, J., Inglehart, R., Leblang, D. (1996). The effect of cultural values on economic development: theory, hypotheses, and some empirical tests. American journal of political science, 40, 607-631.

Hermann, N., Voß, C., Menzel, S. (2013). Wildlife value orientations as predicting factors in support of reintroducing bison and of wolves migrating to Germany. Journal for Nature Conservation, 21(3), 125-132.

Hollenbeck, J. R., Wright, P. M. (2017). Harking, sharking, and tharking: Making the case for post hoc analysis of scientific data.

Inglehart, R. (1997). Modernization and postmodernization: Cultural, economic, and political change in 43 societies. Princeton university press.

Inglehart, R. (2000). Globalization and postmodern values. Washington Quarterly, 23(1), 215-228.

Inglehart, R. F. (2008). Changing values among western publics from 1970 to 2006. West European Politics, 31(1-2), 130-146.

Inglehart, R., Welzel, C. (2010). Changing mass priorities: The link between modernization and democracy. Perspectives on politics, 8(2), 551567.

Jacobs, M. H., Vaske, J. J., Sijtsma, M. T. (2014). Predictive potential of wildlife value orientations for acceptability of management interventions. Journal for Nature Conservation, 22(4), 377-383.

Kaltenbron, B. P., Mehmetoglu, M., Gundersen, V. (2017). Linking Social Values of Wild Reindeer to Planning and Management Options in Southern Norway. Arctic, 129-140.

Kareiva, P. (2008). Ominous trends in nature recreation. Proceedings of the National Academy of Sciences, 105(8), 2757-2758.

Kassambara, A. (2017). Practical guide to cluster analysis in R: Unsupervised machine learning (Vol. 1). STHDA.

Manfredo, M., Teel, T., Bright, A. (2003). Why are public values toward wildlife changing?. Human Dimensions of Wildlife, 8(4), 287-306.

Manfredo, M. J., Teel, T. L., Henry, K. L. (2009). Linking society and environment: A multilevel model of shifting wildlife value orientations in the western United States. Social Science Quarterly, 90(2), 407-427.

Manfredo, M. J., Teel, T. L., Dietsch, A. M. (2016). Implications of human value shift and persistence for biodiversity conservation. Conservation Biology, 30(2), 287-296.

Manfredo, M. J., Bruskotter, J. T., Teel, T. L., Fulton, D., Schwartz, S. H., Arlinghaus, R., ... Sullivan, L. (2017). Why social values cannot be changed for the sake of conservation. Conservation Biology, 31(4), 772-780.

Manfredo, M. J., Teel, T. L., Sullivan, L., Dietsch, A. M. (2017). Values, trust, and cultural backlash in conservation governance: The case of wildlife management in the United States. Biological conservation, 214, 303-311.

Manfredo, M. J., Sullivan, L., Don Carlos, A. W., Dietsch, A. M., Teel, T. L., Bright, A. D., Bruskotter, J. (2018). America's wildlife values: The social context of wildlife management in the US National report from the research project entitled "America's Wildlife Values. Fort Collins, CO: Colorado State University, Department of Human Dimensions of Natural Resources. URL: https://www.fishwildlife.org/application/files/ 9915/4049/1625/AWV_-_National_Final_Report.pdf

Ministero delle Politiche Agricole, Alimentari e Forestali (2009). Relazione sullo stato di attuazione della Legge 11 febbraio 1992, N.157, sulla attività venatoria. Aggiornamento anno 2009. https://www.politicheagricole.it/flex/cm/pages/ ServeBLOB.php/L/IT/IDPagina/357.

Nilsson, D., Fielding, K., Dean, A. (2019). Achieving conservation impact by shifting focus from human attitudes to behaviors behaviours. Conservation Biology.

Nosek, B. A., Ebersole, C. R., DeHaven, A. C., Mellor, D. T. (2018). The preregistration revolution. Proceedings of the National Academy of Sciences, 115(11), 2600-2606.

Pergams, O. R., Zaradic, P. A. (2008). Evidence for a fundamental and pervasive shift away from nature-based recreation. Proceedings of the National Academy of Sciences, 105(7), 2295-2300.

Plant, R. E. (2012). Spatial data analysis in ecology and agriculture using R. cRc Press.
Raadik, J., Cottrell, S. (2007). Wildlife value orientations: An Estonian case study. Human Dimensions of Wildlife, 12(5), 347-357.

Regione Toscana, (2012). Piano agricolo forestale (PRAF) 2012-2015. Bollettino della Regione Toscana dell, 8.

Regione Toscana (2017). La Proliferazione del lupo in Toscana, indagine conoscitiva. http://www.consiglio.regione.toscana.it/ upload/10/CM34/consultazioni/consu914.pdf

Sallusti, L., Pettenella, D., Merlini, P., Romano, R., Salvati, L., Marchetti, M., Corona, P. (2018). Assessing the economic marginality of agricultural lands in Italy to support land use planning. Land use policy, 76, 526-534.

Segal, M., Xiao, Y. (2011). Multivariate random forests. Wiley Interdisciplinary Reviews: Data Mining and Knowledge Discovery, 1(1), 80-87.

Sijtsma, M. T., Vaske, J. J., Jacobs, M. H. (2012). Acceptability of lethal control of wildlife that damage agriculture in the Netherlands. Society Natural Resources, 25(12), 1308-1323.

Soga, M., Gaston, K. J. (2016). Extinction of experience: the loss of human-nature interactions. Frontiers in Ecology and the Environment, 14(2), 94-101.

Teel, T. L., Manfredo, M. J., Jensen, F. S., Buijs, A. E., Fischer, A., Riepe, C., ... Jacobs, M. H. (2010). Understanding the cognitive basis for human-wildlife relationships as a key to successful protected-area management. International Journal of Sociology, 40(3), 104-123.

Van de Kaa, D. J. (2001). Postmodern fertility preferences: From changing value orientation to new behavior behaviour. Population and Development Review, 27, 290-331.

van Eeden, L. M., Dickman, C. R., Ritchie, E. G., Newsome, T. M. (2017). Shifting public values and what they mean for increasing democracy in wildlife management decisions. Biodiversity and conservation, 26(11), 2759-2763.

Vaske, J. J., Jacobs, M. H., Sijtsma, M. T. (2011). Wildlife value orientations and demographics in The Netherlands. European Journal of Wildlife Research, 57(6), 1179-1187.

Zainal Abidin, Z. A., Jacobs, M. H. (2016). The applicability of wildlife value orientations scales to a Muslim student sample in Malaysia. Human dimensions of wildlife, 21(6), 555-566.

Zinn, H. C., Shen, X. S. (2007). Wildlife value orientations in China. Human Dimensions of Wildlife, 12(5), 331-338. 